\title{
Autologous cervical fascia duraplasty in 123 children and adults with Chiari malformation type I: surgical technique and complications
}

\author{
Brian J. Dlouhy, MD, ${ }^{1-3}$ and Arnold H. Menezes, MD1 \\ 1Department of Neurosurgery, University of lowa Hospitals and Clinics, University of lowa Stead Family Children's Hospital; and \\ ${ }^{2}$ lowa Neuroscience Institute and ${ }^{3}$ Pappajohn Biomedical Institute, University of lowa Carver College of Medicine, lowa City, lowa
}

OBJECT Techniques for combined extradural and intradural decompression with expansile duraplasty for Chiari malformation type I (CM-I) have been well described, with various allogenic and autologous materials used for duraplasty. However, the approach and surgical technique used for duraplasty in our treatment of CM-I and developed by the senior author in the 1990s has not been described.

METHODS A prospective database was initiated in March 2003 to denote the use of cervical fascia for duraplasty and incorporate an ongoing detailed record of complications during the surgical treatment of children and adults with CM-I with and without syringomyelia. A total of 389 surgeries for CM-I were performed on 379 patients from March 2003 to June 2016. A total of 123 posterior procedures were performed on 123 patients in which both a posterior fossa extradural and intradural decompression with duraplasty (extra-intradural) was performed. In this paper the authors describe the surgical technique for harvesting and using cervical fascia for duraplasty in the surgical treatment of CM-I and analyze and discuss complications from a prospective database spanning 2003-2016.

RESULTS The authors found that cervical fascia can be harvested in patients of all ages (2-61 years old) without difficulty, and it provides a good substitute for dura in creating an expansile duraplasty in patients with CM-I. Cervical fascia is an elastic-like material with a consistency that allows for a strong watertight closure. Harvesting the cervical fascia graft does not require any further extension of the incision superiorly or inferiorly to obtain the graft. Complications were uncommon in this study of 123 children and adults. The risk of any type of complication (aseptic meningitis, CSF leak, pseudomeningocele, infection, development of hydrocephalus, and need for ventriculoperitoneal shunt) for the 78 patients in the pediatric age group was $0 \%$. The risk of complication in the adult group was $6.7 \%$ (1 patient with aseptic meningitis and 2 patients with CSF leak).

CONCLUSIONS Autologous cervical fascia is easy to obtain in patients of all ages and provides an effective material for duraplasty in the treatment of CM-I. Complications from the combination of both an extradural and intradural decompression with autologous cervical fascia duraplasty are uncommon.

https://thejns.org/doi/abs/10.3171/2018.3.PEDS17550

KEYWORDS Chiari I malformation; tonsillar herniation; tonsillar ectopia; duraplasty; intradural; extradural; syringomyelia; pericranium; allograft; surgical technique

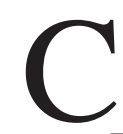
HIARI malformation type I (CM-I) $)^{3,9-11}$ is a condition characterized by the inferior displacement of the cerebellar tonsils through the foramen magnum. The pathophysiology of CM-I tonsillar herniation and CM-I-associated syringomyelia is unclear, but evidence suggests a combination of posterior fossa extradu$\mathrm{ral}^{5,6,20,28,31,32,35,36,40,42}$ and intradural pathology ${ }^{15}$ that occurs in development and creates a partial blockage of CSF flow through the foramen of Magendie and foramen magnum. This pathology leads to the pulsatile impaction of the cerebellar tonsils into the foramen magnum. ${ }^{8}$

Successful treatment of CM-I and CM-I-associated syringomyelia without craniovertebral junction (CVJ) osseoligamentous abnormalities has been achieved with posterior fossa decompression. ${ }^{41}$ The degree of decompression required ${ }^{16,23,27}$ varies across individuals due to

ABBREVIATIONS CJV = craniovertebral junction; $\mathrm{CM}-\mathrm{I}=$ Chiari malformation type I.

SUBMITTED October 3, 2017. ACCEPTED March 29, 2018.

INCLUDE WHEN CITING Published online June 22, 2018; DOI: 10.3171/2018.3.PEDS17550. 
the heterogeneity in the pathophysiology of CM-I. ${ }^{40}$ Some patients only require a posterior fossa extradural decompression to achieve adequate decompression. ${ }^{23,24}$ Other patients, however, will continue to be symptomatic and/ or will have persistent syringomyelia despite an extradural decompression. ${ }^{16,23,27}$ These patients require a combination of both a posterior fossa extradural and intradural decompression with expansile duraplasty to achieve adequate decompression. The intradural decompression may or may not include any of the following depending on the degree of the tonsillar herniation and impaction: lysis of adhesions, opening of foramen of Magendie, and tonsillar reduction. 29,38 The combination of extradural and intradural decompression with expansile duraplasty aims to treat all aspects of the pathophysiology of CM-I with or without syringomyelia. Although opening the dura potentially provides a more complete decompression compared with an extradural decompression alone, the risk for CSF complication is increased. ${ }^{16,25,26}$ In fact, authors of some studies have expressed concerns about opening the dura given the sizeable rates of CSF complications and have utilized a posterior fossa extradural decompression as a first-line treatment in all symptomatic CM-I patients with or without syringomyelia. ${ }^{22,23}$

Techniques for the combined extradural and intradural decompression with expansile duraplasty for CM-I have been well described with various allogenic and autologous materials used for duraplasty. However, the approach and technique developed in the 1990s by the senior author (A.H.M.) has not been described. In this paper we describe our posterior fossa extradural and intradural decompression with cervical fascia duraplasty in the surgical treatment of CM-I in children and adults, with and without syringomyelia. We describe in detail harvesting cervical fascia for duraplasty in patients of all ages. We analyze and discuss complications using this technique from a prospective database spanning 2003-2016.

\section{Methods}

Much of the following methods first appeared in our previously published study. ${ }^{15}$

\section{Patients}

The senior author (A.H.M.) initiated a prospective database of all CVJ abnormalities, ${ }^{14}$ including CM-I,${ }^{29}$ in 1978. In March 2003, we modified the database to denote the use of cervical fascia for duraplasty and incorporate an ongoing detailed record of complications. A total of 389 surgeries for CM-I were performed on 379 patients from March 2003 to June 2016 (Fig. 1). A total of 123 posterior procedures were performed on 123 patients in which both a posterior fossa extradural and intradural decompression with duraplasty (extra-intradural) was performed. One hundred nine of these surgeries were first-time intradural procedures, 6 were repeat intradural decompressions (first surgery was performed at another institution), and 10 had associated osseoligamentous abnormalities requiring occipitocervical fusion at the time of duraplasty. A 1-year follow-up was required for inclusion. No patients presented with signs/symptoms of hydrocephalus. All surgeries were performed by the senior author (A.H.M.) from March 2003 to June 2016 and by the first author (B.J.D.) and senior author (A.H.M.) from July 2015 to June 2016. The University of Iowa IRB approved this study.

\section{Chiari I and Chiari I / Syringomyelia Surgeries in 379 Patients}

(March 2003 - June 2016)

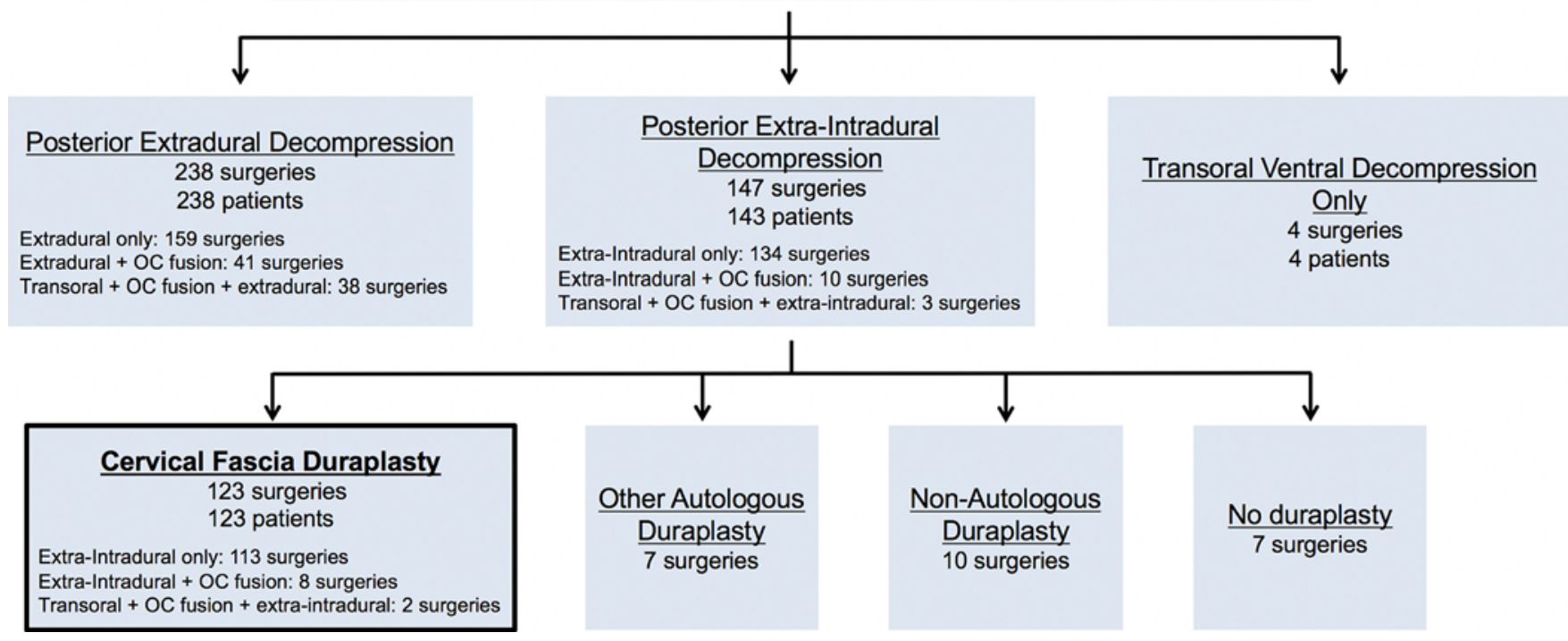

FIG. 1. Flow diagram illustrating the total number of $\mathrm{CM}-\mathrm{I}$ surgeries and patients and breakdown per type of surgery from March 2003 to June 2016 in our prospective database. A total of 123 posterior procedures using autologous cervical fascia for duraplasty were performed on 123 patients in which both an extradural and intradural decompression (extra-intradural) was performed. OC = occipitocervical. Figure is available in color online only. 


\section{CM-I Treatment Algorithm and Indications for Intradural Decompression and Duraplasty}

Important to this study is the selection criteria for performing an intradural decompression and duraplasty following the standard extradural decompression for CM-I. The authors utilized a tailored treatment strategy for each patient with CM-I with and without syringomyelia. All patients underwent preoperative evaluation and if deemed symptomatic, a posterior decompression was offered. Symptomatic patients included patients who presented with Valsalva-induced occipital headaches, bulbar signs/ symptoms, cerebellar signs/symptoms, cranial nerve deficits, or spinal cord signs/symptoms. Intraoperative ultrasonography was utilized through the different stages of the extradural decompression to assess for effective decompression and sufficient subarachnoid space and CSF flow around the tonsils. The presence of CSF behind the tonsils or tonsillar ascent was each a criterion for effective extradural decompression. Although intraoperative ultrasonography is used on all patients, in most patients with CM-I and syringomyelia the authors performed a posterior extra-intradural decompression due to data suggesting that patients with syringomyelia have a significantly greater prevalence of arachnoid veils obstructing the foramen of Magendie..$^{5,29,43}$

\section{Surgical Technique}

\section{Step 1: Posterior Extradural Decompression and Intraoperative Ultrasound Assessment}

All posterior extra-intradural decompressions for CM-I with or without syringomyelia are performed similarly. Prior to intraoperative assessment by ultrasound, a posterior extradural decompression is performed. A posterior occipitocervical incision is made and a subperiosteal dissection performed to expose the occiput, foramen magnum, and C1 lamina. A high-speed electric drill and rongeurs are used to remove approximately $25-30 \mathrm{~mm}$ of the posterior foramen magnum. The occiput is removed superiorly by approximately $30 \mathrm{~mm}$ to the inferior nuchal line. The posterior $25-30 \mathrm{~mm}$ of the superior two-thirds of the C1 lamina is removed and the occipitocervical epidural compressive ligament is excised. Ultrasound is performed to assess the adequacy of the extradural decompression and to determine whether to proceed with intradural decompression and duraplasty (see indications above).

\section{Step 2: Harvesting Cervical Fascia Autograft for Duraplasty}

The edge of the cervical fascia in the midline is isolated with Allis clamps (Figs. 2 and 3, Video 1).

VIDEO 1. Clip showing harvest of autologous cervical fascia for duraplasty. This video is an operative illustration of the step-by-step technique for obtaining autologous cervical fascia for duraplasty in the treatment of CM-I. Copyright Brian J. Dlouhy. Published with permission. Click here to view.

Church scissors are used to conduct a suprafascial dissection and expose $3 \mathrm{~cm}$ of cervical fascia laterally and $4 \mathrm{~cm}$ superiorly and inferiorly. A rake or combination of skin hooks can be used to hold the skin and subcutaneous fat outward. Saline is injected into the subfascial plane to
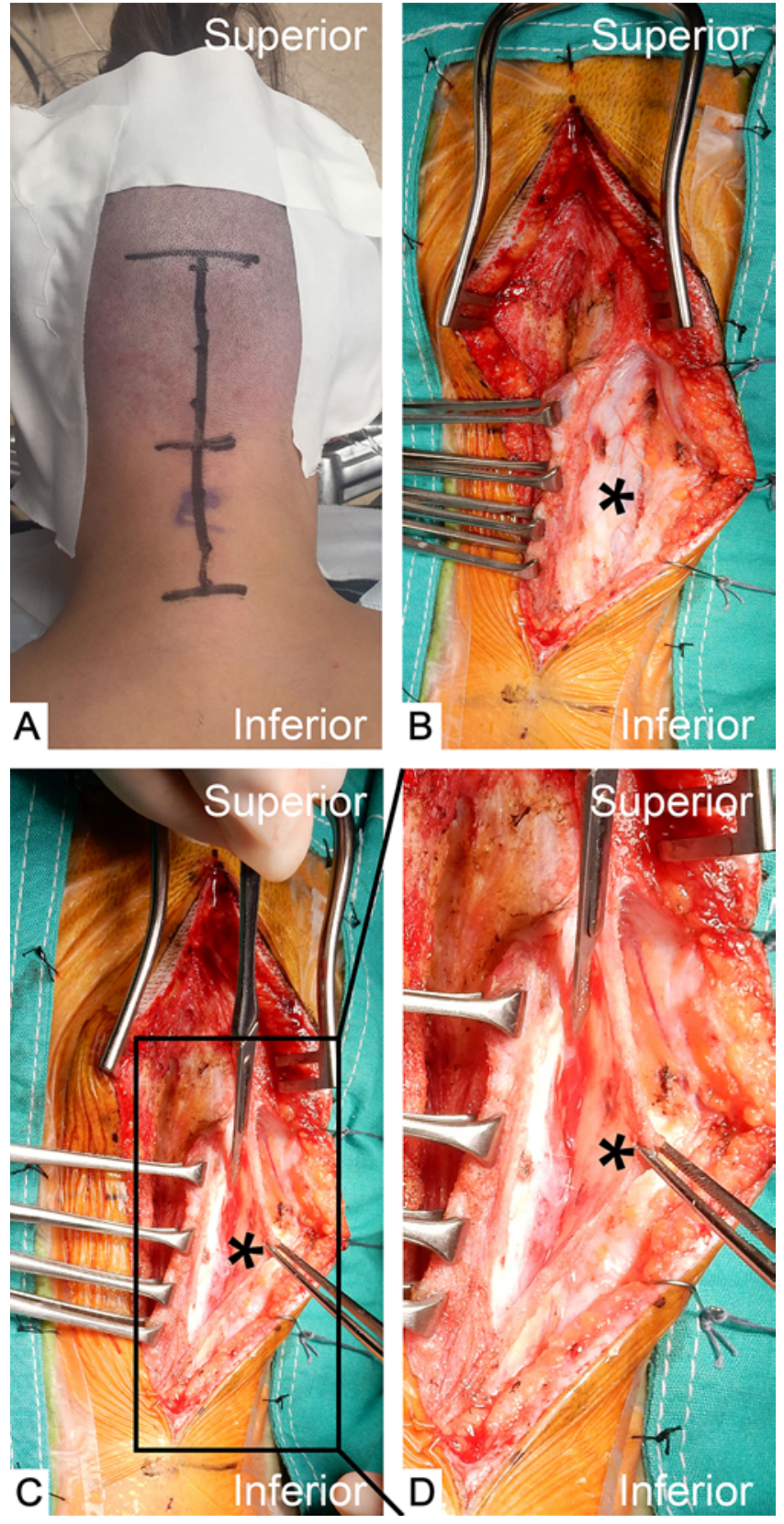

FIG. 2. Intraoperative photographs of harvesting autologous cervical fascia in a 14-year-old girl with CM-I and syringomyelia for use as a dural substitute for duraplasty after extradural and intradural posterior decompression. A: Proposed preoperative occipitocervical incision. B: Allis clamps attached to the cervical fascia on the right with suprafascial dissection to expose $3 \mathrm{~cm}$ of cervical fascia (asterisk). C: Dissection below the cervical fascia and above the cervical musculature with no. 11 and no. 15 blades. D: Inset from panel $\mathrm{C}$ showing the isolated cervical fascia that will be cut and set aside in moist Telfa pads until used for duraplasty. Figure is available in color online only.

assist with dissection from the underlying muscle. A no. 15 blade is used to dissect the fascia from the underlying cervical musculature. Church scissors are used to remove the cervical fascia graft. A $3 \times 2-\mathrm{cm}$ graft is typically obtained. Hemostasis of the underlying musculature is 

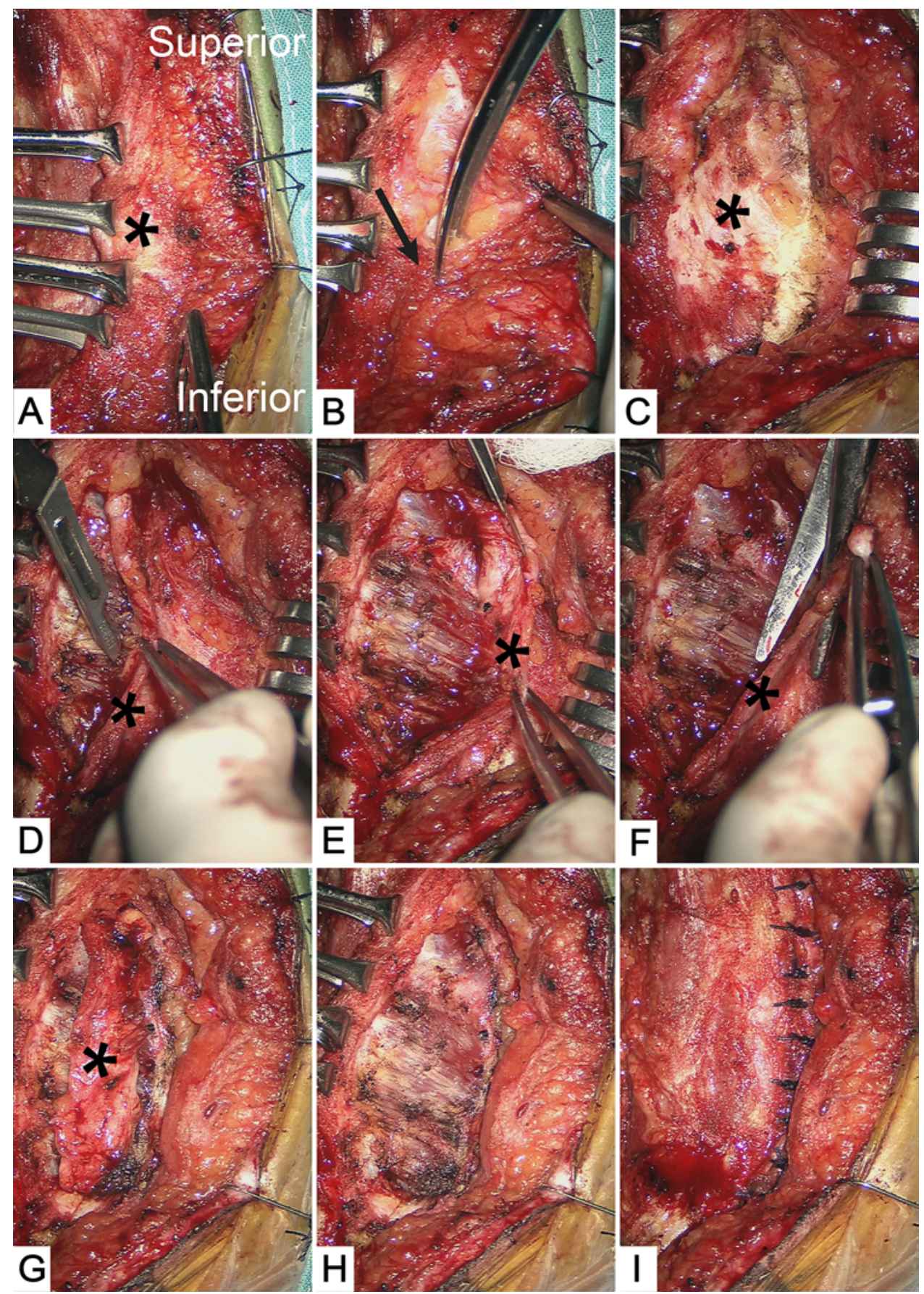

FIG. 3. Intraoperative photographs of the step-by-step approach for harvesting autologous cervical fascia for duraplasty in a 29-yearold man with CM-I and syringomyelia (top of each panel is superior and bottom of each panel is inferior; asterisk indicates cervical fascia). A: Allis clamps attached to the edge of the cervical fascia on the right . B: Church scissors are used to conduct a suprafascial dissection (arrow) and expose $3 \mathrm{~cm}$ of cervical fascia laterally. C: Complete exposure of cervical fascia. Skin hooks can be used to hold the skin and subcutaneous fat in place. D and E: A no. 15 blade is used to dissect the fascia from the underlying cervical musculature. F and G: Church scissors are used to remove the cervical fascia. A $3 \times 2-\mathrm{cm}$ graft is typically obtained. $\mathrm{H}$ and $\mathrm{I}$ : Hemostasis of the underlying musculature is obtained and interrupted closure is performed with polyglycolic acid sutures, thereby allowing a tight fascial approximation with the left-sided fascia when closing. Figure is available in color online only. 
obtained and interrupted closure is performed with polyglycolic acid (Vicryl) sutures, thereby allowing a tight fascial approximation with the opposite-sided fascia during closure. The cervical fascia graft can be trimmed to the appropriate size and any extraneous fat or muscle can be removed if present.

\section{Step 3: Posterior Intradural Decompression With Cervical Fascia Duraplasty}

Using a surgical microscope under high-power magnification, the posterior fossa dura is opened starting at the superolateral quadrant on the right and proceeding down to the midline at the foramen magnum and then along the dorsal axis of the cervical canal toward the lamina of $\mathrm{C} 1$ in a curvilinear-like fashion (Fig. 4). Care is taken to leave the arachnoid intact during dural incision. Stay sutures hold apart the exposure. Hemostasis in the venous sinuses is secured with titanium clips.

Upon completion of the dural opening, the arachnoid is inspected and divided in the midline and held apart temporarily and attached to the dural edges with titanium clips. Arachnoid adhesions are lysed and the foramen of Magendie (opening of fourth ventricle) is explored and any adhesions and arachnoid veils are cauterized and lysed.

Cerebellar tonsillar reduction is performed through low-power bipolar pia-arachnoid electric coagulation of the cerebellar tonsils such that the tonsils ascend upward and outward. This opens the roof of the fourth ventricle and exposes the egress of the fourth ventricle. The integrity of the pia mater is maintained to avoid potential adhesion, scarring, and recurrence. Modified cisterna magna reconstruction is performed with placement of a patulous elliptical cervical fascia dural graft previously harvested from the patient. Typically, the side of the fascia not adjacent to the cervical musculature should face the intradural contents when suturing the graft. Cervical fascia is elastic and pliable and when sutured, the fascia fills in the suture holes, allowing a watertight closure. Additionally, the fascia will billow in and out with the CSF pulsations, allowing for even more expansion without requiring a large duraplasty. Tisseel is layered over the duraplasty incision and a piece of Gelfoam is placed over the exposed dura to prevent muscular adherence to the dura. The wound is closed meticulously in a multilayered muscular and fascial closure to ensure musculoligamentous stability.

\section{Results \\ Demographics}

A total of 123 patients underwent posterior fossa extraintradural decompression with cervical fascia duraplasty (Fig. 1). The mean age of patients was 17.6 years (range 2-61 years; Table 1). Seventy-eight patients $(63.4 \%)$ were pediatric $(<18$ years old) and 45 patients $(36.6 \%)$ were adults ( $\geq 18$ years old). A total of 81 females and 42 males underwent surgery. The mean tonsillar herniation was $15.2 \mathrm{~mm}$ (range 4.5-26.4 mm). Cervicomedullary compression with cervicomedullary buckle was observed in 90 patients (73.2\%). Syringomyelia occurred in 89 patients $(72.4 \%)$. No hydrocephalus was observed in any of the pa- tients preoperatively. Associated CVJ abnormalities were observed in 10 patients (8.1\%). Six surgeries (4.8\%) were repeat intradural procedures in which the first surgery was performed at another institution. Follow-up was at least 1 year from surgery (mean 4.8 years).

\section{Complications}

Complications were assessed in the immediate postoperative period; at 3, 6, and 12 months postoperatively; and for the entirety of the follow-up period for each of the 123 patients (Table 1). No intraoperative complications occurred with graft harvest or graft placement in any of the patients. No postoperative complications occurred in the 78 patients in the pediatric age group $(<18$ years old). Only 3 CSF complications were observed in the 123 patients, all of which occurred in the adult group. Aseptic meningitis, defined as severe nonbacterial meningitis that resulted in postoperative headache, fevers, prolonged vomiting, and/or readmission for these symptoms, occurred in 1 adult patient. CSF leak occurred in 2 adult patients, both of which occurred in 2005. One patient required reexploration and a small leak was noted at the edge and the end of the autologous cervical fascial graft and the native dura. A single stitch was placed here and the patient did well postoperatively. The other leak was treated with a lumbar drain for 5 days, which was effective in eliminating the CSF leak, and the patient tolerated this without worsening symptoms or recurrent symptoms in the future.

The only radiographic pseudomeningocele or symptoms of a pseudomeningocele were the 2 patients described above who presented with a CSF leak. No superficial or deep infections occurred. No patients developed hydrocephalus on imaging or with signs/symptoms. Therefore, no patients required ventriculoperitoneal shunting for hydrocephalus. Additionally, no patients required ventriculoperitoneal shunting for any reason, including persistent syringomyelia, CSF leak, or pseudomeningocele.

Four adults and no pediatric patients required readmission within the 3-month postoperative period. These included the 2 patients who developed a pseudomeningocele and CSF leak requiring treatment as described above, the adult patient who developed aseptic meningitis, and a fourth patient who was admitted for migraine headache management. One adult patient and 1 pediatric patient required a future repeat intradural reoperation for increase in syrinx size, resulting in increased symptoms. On reexploration, no complications were observed from the graft-it was intact without scarring-and more aggressive intradural lysis of adhesions was performed. This procedure resulted in improvement in symptoms and decrease in the syrinx size on follow-up.

\section{Discussion}

\section{Key Results and Interpretation}

This is the first study to describe the surgical technique and use of an autologous cervical fascia duraplasty in the treatment of CM-I in patients of all ages (children and adults) with and without syringomyelia. We found that cervical fascia can be harvested in patients of all ages 

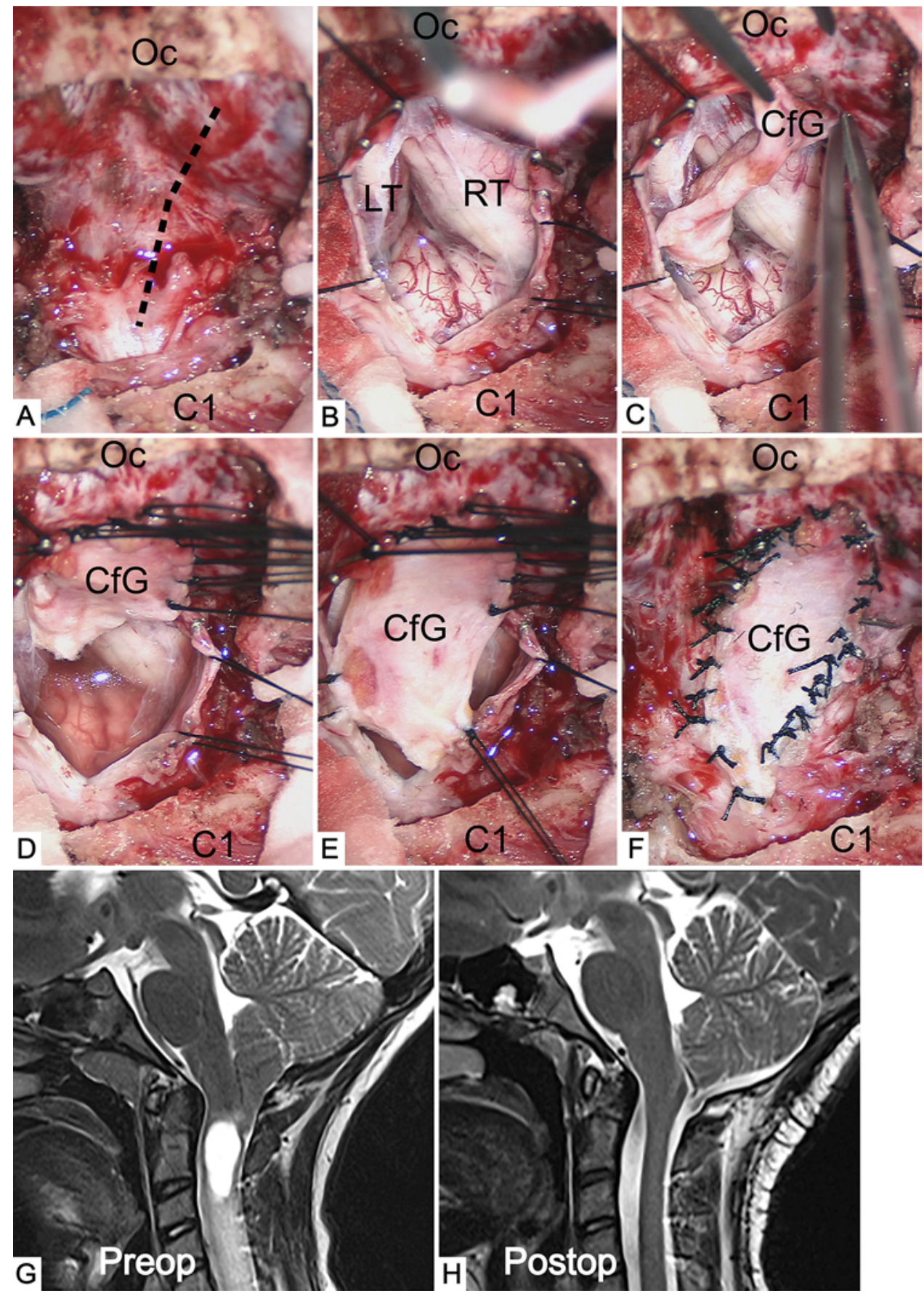

FIG. 4. A 13-year-old girl with CM-I and syringomyelia who underwent extradural and intradural decompression with cervical fascia duraplasty. A: Suboccipital craniectomy from the inferior nuchal line to the foramen magnum, superior two-thirds $\mathrm{C} 1$ laminectomy, and excision of occipitocervical epidural compressive band. Dashed line illustrates proposed dural opening. Ultrasound is used at this point to assess for adequate decompression. If not adequate, the autologous cervical fascia is harvested and the dura opened. B: Dura opened along proposed dashed line (panel A) and held back with stay sutures. Adhesions were lysed, the foramen of Magendie opened, and the tonsils reduced with pia-arachnoid coagulation. C-F: The cervical fascia graft (CfG) is sutured to the native dura in a patulous but watertight fashion. G: Preoperative sagittal T2-weighted MR image demonstrating the tonsillar herniation, cervicomedullary kink, and large cervical syrinx. H: Three-year postoperative sagittal T2-weighted MR image revealing good decompression of the cervicomedullary junction with CSF surrounding the tonsils, brainstem, and upper cervical spinal cord. Ascent of the cervicomedullary junction and complete resolution of the cervical syrinx is demonstrated. $\mathrm{Oc}=$ occipital bone. Figure is available in color online only. 
TABLE 1. Demographics and complications associated with cervical fascia duraplasty after extradural and intradural decompression for CM-I in 123 children and adults

\begin{tabular}{|c|c|c|c|}
\hline Variable & All Patients $(n=123)$ & Pediatric (<18 yrs; $n=78$ ) & Adult $(\geq 18$ yrs; $n=45)$ \\
\hline \multicolumn{4}{|l|}{ Demographics } \\
\hline Mean age, yrs (range) & $17.6(2-61)$ & $10.4(2-17)$ & $30.1(18-61)$ \\
\hline Male gender, $\mathrm{n}(\%)$ & $42(34.1)$ & $30(38.5)$ & $12(26.7)$ \\
\hline Mean tonsillar herniation, mm (range) & $15.2(4.5-26.4)$ & $15.9(4.5-26.0)$ & $14.0(5.0-26.4)$ \\
\hline Cervicomedullary kink/buckle, n (\%) & $90(73.2)$ & $60(76.9)$ & $30(66.7)$ \\
\hline Syringomyelia, $n(\%)$ & $89(72.4)$ & $59(75.6)$ & $30(66.7)$ \\
\hline Hydrocephalus, $n(\%)$ & $0(0)$ & $0(0)$ & $0(0)$ \\
\hline Associated CVJ osseoligamentous abnormality, n (\%) & $10(8.1)$ & $6(7.7)$ & $4(8.9)$ \\
\hline Repeat CM-I decompression w/ duraplasty, n (\%) & $6(4.9)$ & $6(7.7)$ & $0(0)$ \\
\hline Mean total follow-up, yrs (range) & $4.8(1-13.1)$ & $4.8(1-12.9)$ & $4.8(1-13.1)$ \\
\hline \multicolumn{4}{|l|}{ Postop complications, $\mathrm{n}(\%)$} \\
\hline Aseptic meningitis & $1(0.8)$ & $0(0)$ & $1(2.2)$ \\
\hline CSF leak* & $2(1.6)$ & $0(0)$ & $2(4.4)$ \\
\hline Pseudomeningocele* & $2(1.6)$ & $0(0)$ & $2(4.4)$ \\
\hline Infection & $0(0)$ & $0(0)$ & $0(0)$ \\
\hline Development of hydrocephalus & $0(0)$ & $0(0)$ & $0(0)$ \\
\hline Need for ventriculoperitoneal shunt & $0(0)$ & $0(0)$ & $0(0)$ \\
\hline Need for reoperation due to other complication $†$ & $1(0.8)$ & $0(0)$ & $1(2.2)$ \\
\hline Need for readmission & $4(3.25)$ & $0(0)$ & $4(8.9)$ \\
\hline Need for reoperation for $\mathrm{CM}-\mathrm{I} /$ syrinx in future unrelated to complications & $2(1.6)$ & $1(1.3)$ & $1(2.2)$ \\
\hline
\end{tabular}

* The only radiographic pseudomeningocele or symptoms of a pseudomeningocele were the 2 patients who presented with a CSF leak.

$\dagger$ One adult patient required readmission and reoperation for a subcutaneous fluid collection associated with the use of bone morphogenetic protein; this complication was described and reported in Lindley TE, Dahdaleh NS, Menezes AH, et al: Complications associated with recombinant human bone morphogenetic protein use in pediatric craniocervical arthrodesis. J Neurosurg Pediatr 7:468-474, 2011.

(2-61 years old) without difficulty, and it provides a good substitute for dura in creating an expansile duraplasty. It is elastic and billows in and out with CSF pulsations, and its consistency allows obliteration of suture holes for a strong watertight closure. Harvesting the cervical fascia graft does not require any further extension of the incision superiorly or inferiorly to obtain the graft. Complications were uncommon in this prospective study of 123 children and adults.

\section{Complications}

Postoperative complications associated with intradural exploration and duraplasty for the surgical treatment of CM-I vary significantly in the literature. Studies have found the risk of complications to be between $3 \%$ and $40 \%$ and consist of aseptic meningitis, pseudomeningocele, CSF leak, postoperative hydrocephalus, ${ }^{18}$ wound infection, and meningitis. ${ }^{13,16,21,33}$ CSF complications specifically have been reported to occur in 3\%-19\% of reported series. ${ }^{16,21,25,26}$ In this study we found the complication risk profile was very small using a cervical fascia duraplasty. The risk of any type of complication for the 78 patients in the pediatric age group was $0 \%$, and the risk of complication in the adult group was $6.7 \%$ (1 patient with aseptic meningitis and 2 patients with CSF leak). Similarly, others have also demonstrated small rates of complications with the combination of extradural and intradural CM-I decompression with duraplasty. ${ }^{21}$

\section{Autologous and Allogenic Materials Used in Duraplasty}

The types of autologous, allogenic, and synthetic materials used for duraplasty in CM-I are extensive. ${ }^{1,34}$ These materials include autologous and allogenic pericranium, ${ }^{4,39,45}$ autologous and allogenic fascia lata, ${ }^{2}$ autologous ligamentum nuchae, lyophilized cadaveric dura, ${ }^{45}$ acellular human dermis allograft (AlloDerm; Allergan, Inc.), ${ }^{12,13}$ bovine pericardium (DuraGuard; Baxter, Inc.), fetal bovine tissue (Durepair; Medtronic, Inc.), processed bovine collagen matrix (DuraGen; Integra, Inc., and DuraMatrix; Stryker, Inc.), ${ }^{13}$ synthetic Gore-Tex, expanded polytetrafluoroethylene, ${ }^{4,30,37}$ autologous posterior atlantooccipital membrane,${ }^{44}$ autologous splenius capitis muscle flap, ${ }^{17}$ and porcine small intestinal submucosa (Durasis; Cook Medical). ${ }^{7}$ A survey of pediatric neurosurgeons in July 1998 by the AANS revealed wide variation in preferred material for duraplasty. ${ }^{19}$

Others have proposed criteria for an optimal dura mater graft. Theoretically, the ideal graft would provide watertight dural closure without inflammatory reaction against the leptomeninges or cortex; induce no adhesions to the brain tissue or arachnoid; provide protection against external bacteria; be readily and easily available, durable, flexible, elastic, easily prepared, inexpensive, easily sterilized and handled, and easily shaped; and be known to be chemically inert and nontoxic. ${ }^{45}$ Only a few studies have compared one graft or multiple grafts against each other. ${ }^{1}$ However, these studies are hindered by many limitations. 
Therefore, no study has shown superiority of either autologous or allogenic grafts for duraplasty in CM-I.

Autologous cervical fascia meets many of the criteria for an optimal dura mater graft and harvesting autologous cervical fascia does not require extension of the incision or a separate incision. The most common autologous material used for duraplasty reported in the literature is the pericranium. However, most techniques for harvesting pericranium require extension of the incision superiorly beyond the need for adequate exposure for the CM-I posterior fossa decompression. Although theoretical, an additional advantage of autologous cervical fascia is that it is unlikely to induce bone development (a risk more associated with younger children with CM-I), unlike other materials, such as pericranium, which could potentially induce bone growth and result in future compression and symptom recurrence.

\section{Limitations}

Although this study was prospective in nature, it was not a randomized study. Therefore, there is a selection bias of patients with CM-I who underwent intradural exploration and duraplasty. For most patients with syringomyelia, an extra-intradural decompression is performed to ensure egress from the foramen of Magendie. As discussed, we individualize the treatment strategy using intraoperative ultrasonography to determine the need for greater decompression through intradural exploration, tonsillar reduction, and duraplasty. Therefore, not all patients undergo intradural exploration and duraplasty. However, with this individualized strategy, it appears the risk of complication with an intradural procedure and autologous cervical fascia graft is quite minimal.

\section{Conclusions}

Autologous cervical fascia is easy to obtain in patients of all ages and provides an effective material for duraplasty in the treatment of CM-I. Complications from the combination of both an extradural and intradural decompression with cervical fascia duraplasty are uncommon.

\section{References}

1. Abla AA, Link T, Fusco D, Wilson DA, Sonntag VK: Comparison of dural grafts in Chiari decompression surgery: Review of the literature. J Craniovertebr Junction Spine 1:29-37, 2010

2. Abuzayed B, Kafadar AM, Oğuzoğlu SA, Canbaz B, Kaynar MY: Duraplasty using autologous fascia lata reenforced by on-site pedicled muscle flap: technical note. J Craniofac Surg 20:435-438, 2009

3. Arnold J: Myelocyste, Transposition von Gewebskeimen und Sympodie. Beitr Pathol Anat 16:1-28, 1894

4. Attenello FJ, McGirt MJ, Garcés-Ambrossi GL, Chaichana KL, Carson B, Jallo GI: Suboccipital decompression for Chiari I malformation: outcome comparison of duraplasty with expanded polytetrafluoroethylene dural substitute versus pericranial autograft. Childs Nerv Syst 25:183-190, 2009

5. Badie B, Mendoza D, Batzdorf U: Posterior fossa volume and response to suboccipital decompression in patients with Chiari I malformation. Neurosurgery 37:214-218, 1995

6. Bagci AM, Lee SH, Nagornaya N, Green BA, Alperin N: Automated posterior cranial fossa volumetry by MRI: appli- cations to Chiari malformation type I. AJNR Am J Neuroradiol 34:1758-1763, 2013

7. Bejjani GK, Zabramski J: Safety and efficacy of the porcine small intestinal submucosa dural substitute: results of a prospective multicenter study and literature review. J Neurosurg 106:1028-1033, 2007

8. Buell TJ, Heiss JD, Oldfield EH: Pathogenesis and cerebrospinal fluid hydrodynamics of the Chiari I malformation. Neurosurg Clin N Am 26:495-499, 2015

9. Chiari H: Ueber Veranderungen des Kleinhirns, des Pons und der Medulla oblongata Infolge von congenitaler Hydrocephalie des Grosshirns. Denkschriften Kais Akad Wiss Math-Naturw 63:71-116, 1896

10. Chiari H: Ueber Veränderungen des Kleinhirns infolge von Hydrocephalie des Grosshirns. Dtsch Med Wochenschr 17:1172-1175, 1891

11. Cleland J: Contribution to the study of spina bifida, encepahlocele, and anencephalus. J Anat Physiol 17:257-292, 1883

12. Costantino PD, Wolpoe ME, Govindaraj S, Chaplin JM, Sen $\mathrm{C}$, Cohen M, et al: Human dural replacement with acellular dermis: clinical results and a review of the literature. Head Neck 22:765-771, 2000

13. Danish SF, Samdani A, Hanna A, Storm P, Sutton L: Experience with acellular human dura and bovine collagen matrix for duraplasty after posterior fossa decompression for Chiari malformations. J Neurosurg 104 (1 Suppl):16-20, 2006

14. Dlouhy BJ, Dahdaleh NS, Menezes AH: Evolution of transoral approaches, endoscopic endonasal approaches, and reduction strategies for treatment of craniovertebral junction pathology: a treatment algorithm update. Neurosurg Focus 38(4):E8, 2015

15. Dlouhy BJ, Dawson JD, Menezes AH: Intradural pathology and pathophysiology associated with Chiari I malformation in children and adults with and without syringomyelia. J Neurosurg Pediatr 20:526-541, 2017

16. Durham SR, Fjeld-Olenec K: Comparison of posterior fossa decompression with and without duraplasty for the surgical treatment of Chiari malformation Type I in pediatric patients: a meta-analysis. J Neurosurg Pediatr 2:42-49, 2008

17. Elsahy NI, Achecar FA: Use of the splenius capitis muscle flap for reconstruction of the posterior neck and skull in complicated Arnold-Chiari malformation. Plast Reconstr Surg 93:1082-1086, 1994

18. Guan J, Riva-Cambrin J, Brockmeyer DL: Chiari-related hydrocephalus: assessment of clinical risk factors in a cohort of 297 consecutive patients. Neurosurg Focus 41(5):E2, 2016

19. Haroun RI, Guarnieri M, Meadow JJ, Kraut M, Carson BS: Current opinions for the treatment of syringomyelia and Chiari malformations: survey of the Pediatric Section of the American Association of Neurological Surgeons. Pediatr Neurosurg 33:311-317, 2000

20. Heiss JD, Suffredini G, Bakhtian KD, Sarntinoranont M, Oldfield EH: Normalization of hindbrain morphology after decompression of Chiari malformation Type I. J Neurosurg 117:942-946, 2012

21. Hoffman CE, Souweidane MM: Cerebrospinal fluid-related complications with autologous duraplasty and arachnoid sparing in type I Chiari malformation. Neurosurgery 62 (3 Suppl 1):156-161, 2008

22. Isu T, Sasaki H, Takamura H, Kobayashi N: Foramen magnum decompression with removal of the outer layer of the dura as treatment for syringomyelia occurring with Chiari I malformation. Neurosurgery 33:845-850, 1993

23. Kennedy BC, Kelly KM, Phan MQ, Bruce SS, McDowell MM, Anderson RC, et al: Outcomes after suboccipital decompression without dural opening in children with Chiari malformation Type I. J Neurosurg Pediatr 16:150-158, 2015 
24. Kennedy BC, Nelp TB, Kelly KM, Phan MQ, Bruce SS, McDowell MM, et al: Delayed resolution of syrinx after posterior fossa decompression without dural opening in children with Chiari malformation Type I. J Neurosurg Pediatr 16:599-606, 2015

25. Lee A, Yarbrough CK, Greenberg JK, Barber J, Limbrick DD, Smyth MD: Comparison of posterior fossa decompression with or without duraplasty in children with Type I Chiari malformation. Childs Nerv Syst 30:1419-1424, 2014

26. Litvack ZN, Lindsay RA, Selden NR: Dura splitting decompression for Chiari I malformation in pediatric patients: clinical outcomes, healthcare costs, and resource utilization. Neurosurgery 72:922-929, 2013

27. McGirt MJ, Attenello FJ, Datoo G, Gathinji M, Atiba A, Weingart JD, et al: Intraoperative ultrasonography as a guide to patient selection for duraplasty after suboccipital decompression in children with Chiari malformation Type I. J Neurosurg Pediatr 2:52-57, 2008

28. Menezes AH: Craniovertebral junction abnormalities with hindbrain herniation and syringomyelia: regression of syringomyelia after removal of ventral craniovertebral junction compression. J Neurosurg 116:301-309, 2012

29. Menezes AH, Greenlee JD, Donovan KA: Honored guest presentation: lifetime experiences and where we are going: Chiari I with syringohydromyelia-controversies and development of decision trees. Clin Neurosurg 52:297-305, 2005

30. Messing-Jünger AM, Ibáñez J, Calbucci F, Choux M, Lena G, Mohsenipour I, et al: Effectiveness and handling characteristics of a three-layer polymer dura substitute: a prospective multicenter clinical study. J Neurosurg 105:853-858, 2006

31. Milhorat TH, Chou MW, Trinidad EM, Kula RW, Mandell M, Wolpert C, et al: Chiari I malformation redefined: clinical and radiographic findings for 364 symptomatic patients. Neurosurgery 44:1005-1017, 1999

32. Nishikawa M, Sakamoto H, Hakuba A, Nakanishi N, Inoue Y: Pathogenesis of Chiari malformation: a morphometric study of the posterior cranial fossa. J Neurosurg 86:40-47, 1997

33. Parker SR, Harris P, Cummings TJ, George T, Fuchs H, Grant G: Complications following decompression of Chiari malformation Type I in children: dural graft or sealant? J Neurosurg Pediatr 8:177-183, 2011

34. Rosen DS, Wollman R, Frim DM: Recurrence of symptoms after Chiari decompression and duraplasty with nonautologous graft material. Pediatr Neurosurg 38:186-190, 2003

35. Sgouros S, Kountouri M, Natarajan K: Posterior fossa volume in children with Chiari malformation Type I. J Neurosurg 105 (2 Suppl):101-106, 2006

36. Sgouros S, Kountouri M, Natarajan K: Skull base growth in children with Chiari malformation Type I. J Neurosurg 107 (3 Suppl):188-192, 2007

37. Shimizu S, Koizumi H, Kurita M, Utsuki S, Oka H, Fujii K: Duraplasty in the posterior fossa using a boat-shaped sheet of expanded polytetrafluoroethylene. Neurol Med Chir (Tokyo) 47:379-381, 2007

38. Stanko KM, Lee YM, Rios J, Wu A, Sobrinho GW, Weingart
JD, et al: Improvement of syrinx resolution after tonsillar cautery in pediatric patients with Chiari Type I malformation. J Neurosurg Pediatr 17:174-181, 2016

39. Stevens EA, Powers AK, Sweasey TA, Tatter SB, Ojemann RG: Simplified harvest of autologous pericranium for duraplasty in Chiari malformation Type I. Technical note. J Neurosurg Spine 11:80-83, 2009

40. Taylor DG, Mastorakos P, Jane JA Jr, Oldfield EH: Two distinct populations of Chiari I malformation based on presence or absence of posterior fossa crowdedness on magnetic resonance imaging. J Neurosurg 126:1934-1940, 2017

41. Tubbs RS, Beckman J, Naftel RP, Chern JJ, Wellons JC III, Rozzelle CJ, et al: Institutional experience with 500 cases of surgically treated pediatric Chiari malformation Type I. J Neurosurg Pediatr 7:248-256, 2011

42. Tubbs RS, Hill M, Loukas M, Shoja MM, Oakes WJ: Volumetric analysis of the posterior cranial fossa in a family with four generations of the Chiari malformation Type I. J Neurosurg Pediatr 1:21-24, 2008

43. Tubbs RS, Smyth MD, Wellons JC III, Oakes WJ: Arachnoid veils and the Chiari I malformation. J Neurosurg 100 (5 Suppl Pediatrics):465-467, 2004

44. Tubbs RS, Wellons JC III, Blount JP, Oakes WJ: Posterior atlantooccipital membrane for duraplasty. Technical note. J Neurosurg 97 (2 Suppl):266-268, 2002

45. Vanaclocha V, Saiz-Sapena N: Duraplasty with freeze-dried cadaveric dura versus occipital pericranium for Chiari type I malformation: comparative study. Acta Neurochir (Wien) 139:112-119, 1997

\section{Disclosures}

The authors report no conflict of interest concerning the materials or methods used in this study or the findings specified in this paper.

\section{Author Contributions}

Conception and design: both authors. Acquisition of data: both authors. Analysis and interpretation of data: both authors. Drafting the article: Dlouhy. Critically revising the article: both authors. Reviewed submitted version of manuscript: both authors. Approved the final version of the manuscript on behalf of both authors: Dlouhy. Administrative/technical/material support: Menezes. Study supervision: both authors.

\section{Supplemental Information \\ Videos}

Video 1. https://vimeo.com/266120726.

\section{Correspondence}

Brian J. Dlouhy: University of Iowa Children's Hospital, University of Iowa Hospitals and Clinics, Iowa City, IA. brian-dlouhy@ uiowa.edu. 